\title{
Relationship of cuticle development with water loss and texture of pepper fruit
}

\author{
Ayako Konishi, Satoshi Terabayashi, and Akihiro Itai
}

\begin{abstract}
Postharvest water loss in pepper fruit (Capsicum annuum L.) reduces its shelf life. Fruit texture is one of the most important components of fruit quality for consumers. In this study, the anatomical traits of pepper fruit related to postharvest water loss and texture were assessed. There was a strong positive relationship between postharvest water loss and the thickness of the cuticular membrane, cuticular weight, total cutin weight, and polysaccharide-cutan weight. An amorphous fibrous structure that forms a path for diffusion and increases water loss was observed in the thick cuticle of the pericarp. In addition, positive correlations between the hardness of the exocarp and the weight of cuticular membrane, cutin content, and polysaccharide-cutan content were found. These results indicate that the thickness of the cuticular membrane wedged between subepidermal cells may influence water loss through the pericarp of pepper fruit and fruit with a high cutin and polysaccharide content have a hard tough texture.
\end{abstract}

Key words: cuticular membrane, water loss, texture, Capsicum annuum.

Résumé : La durée de conservation du poivron (Capsicum annuum L.) est plus courte quand le fruit perd de l'eau après la récolte. Or, pour le consommateur, la texture est une des principales composantes de la qualité du fruit. Les auteurs ont évalué les caractères anatomiques du poivron en regard de la perte d'eau après la cueillette ainsi que de la texture du fruit. La perte d'eau post-messianique présente une forte corrélation positive avec l'épaisseur de la membrane de la cuticule, le poids de la cuticule, le poids de la cutine et le poids des polysaccharides incluant la cutane. Les auteurs ont noté la formation d'une structure fibreuse amorphe facilitant la diffusion de l'eau, ce qui en accroît la perte, dans l'épaisse cuticule du péricarpe. Ils ont aussi relevé des corrélations positives entre la dureté de l'exocarpe et le poids de la membrane cuticulaire, la teneur en cutine et la concentration de polysaccharides incluant la cutane. Ces résultats laissent croire que l'épaisseur de la membrane cuticulaire qui sépare les cellules sous-épidermiques pourrait influer sur la perte d'eau à travers le péricarpe du poivron et que les fruits riches en cutine et en polysaccharides se caractérisent par une texture dure et fibreuse. [Traduit par la Rédaction]

Mots-clés : membrane cuticulaire, perte d'eau, texture, Capsicum annuum.

\section{Introduction}

Pepper is an important horticultural crop globally. Of the five cultivated species of pepper, Capsicum annuum is the most widely used in Japan as a vegetable, spice, and food colorant. There are many local cultivars of C. annuum in Japan.

Generally, peppers suffer from high postharvest water loss at every stage of ripening because the fruit is hollow. This water loss reduces the economic value of the fruit because of the subsequent reductions in freshness, firmness, and glossiness. High postharvest water loss is, therefore, an important defect in peppers for consumption as a vegetable. To control the postharvest water loss, Lownds et al. (1994) reported the effect of storage temperature and packaging. However, methods for reducing postharvest water loss by storage condition will not contribute to a fundamental solution. Therefore, it is necessary to alleviate high water loss through the process of breeding.

Received 2 February 2021. Accepted 11 April 2021.

A. Konishi. Kyoto Prefectural Agriculture, Forestry and Fisheries Technology Center, Kameoka, Kyoto 621-0806, Japan.

S. Terabayashi. Faculty of Agriculture, Setsunan University, Hirakata, Osaka 573-0101, Japan.

A. Itai. Graduate School of Life and Environmental Sciences, Kyoto Prefectural University, Seika, Kyoto, 619-0244, Japan.

Corresponding author: A. Konishi (email: a-konishi01@pref.kyoto.lg.jp).

() 2021 The Author(s). This work is licensed under a Creative Commons Attribution 4.0 International License (CC BY 4.0), which permits unrestricted use, distribution, and reproduction in any medium, provided the original author(s) and source are credited. 
The cuticular membrane covering the fruit surface is thought to play a role in fruit water loss (Saladié et al. 2007) and resistance to pathogens and insects (Saladié et al. 2007; Isaacson et al. 2009). In several studies, associations between the amounts of cuticle, cuticular wax, and cutin, and postharvest water loss have been investigated. A negative correlation between the rate of water loss and total amount of cuticular wax in pepper fruit was found in some studies (Lownds et al. 1993; Maalekuu et al. 2004) but not others (Parsons et al. 2012). Additionally, Maalekuu et al. (2005) found no correlation between fruit water loss and whole cuticular weight, whereas Parsons et al. (2012) found a positive correlation between fruit water loss and total cutin monomer amounts in pepper fruit. Moreover, Parsons et al. (2012) reported that fruits containing higher amounts of terpenoids relative to aliphatic wax in the cuticle tended to have a higher rate of water loss. Thus, the role of the cuticular membrane in postharvest water loss remains unclear.

Several studies of the relationships between the physiological properties of pepper fruit and postharvest water loss have been conducted (Maalekuu et al. 2005; Smith et al. 2006). Maalekuu et al. (2005) found negative correlations between the rate of water loss and fruit fresh weight, fruit pericarp weight, pericarp surface area, and initial water content, but there was a positive correlation between the rate of water loss and dry matter content. There was no relationship between the rate of water loss and pericarp thickness.

Chaïb et al. (2007) found correlations between the cellular structure of the pericarp and texture of tomato fruit. Fruit texture is one of the most important components of fruit quality for consumers. There are several studies on the influence of storage and blanching on fruit texture in bell pepper (Papageorge et al. 2003; Hernández-Carrión et al. 2014), but few studies regarding breeding to improve fruit texture.

The objective of this study was to clarify the effects of cuticle development and anatomical traits on postharvest water loss and texture of pepper fruit.

\section{Materials and methods}

\section{Plant materials}

The plant materials included 6 commercial cultivars, 21 genetic resources (Plant Genetic and Breeding Laboratory, Shinshu University; Matsushima et al. 2009), and 4 breeding lines (Biotechnology Research Department, Kyoto Prefectural Agriculture, Forestry and Fisheries Technology Center) (Table 1). Thirty-one cultivars were selected for character of fruit according to future breeding, elongated shape, and red color in mature fruit, which were grown in the greenhouse of the Kyoto Prefectural Agriculture, Forestry and Fisheries Technology Center during 2017 and 2020.
Seeds were sown in vermiculite, and individual seedlings were transplanted into 10-L pots filled with nursery soil (Takii \& Co. Ltd., Kyoto, Japan). Seedlings of each cultivar were grown in the greenhouse under a controlled environment of a minimum temperature of $16{ }^{\circ} \mathrm{C}$ with ambient sunlight and watered either once or twice daily. Mature green fruits of almost maximum size without visible defects were harvested and quickly transported in plastic bags to the laboratory.

\section{Postharvest water loss}

Ten mature green fruits of each cultivar were harvested except for S3194, S3197, and S3226; these cultivars did not produce enough fruit, and five fruits were harvested and stored in an incubator at $22{ }^{\circ} \mathrm{C}$ and $56 \%$ relative humidity. Fruit weight was measured just before storage and $3 \mathrm{~d}$ after storage. The methods of Leide et al. (2007) for surface area analysis were modified. The pepper fruits were assumed to be cone shaped. Two photographs of the conical surface of the fruit were obtained and the fruit surface area was calculated using the following formula

$$
\text { fruit surface area }\left(\mathrm{cm}^{2}\right)=2 \times \pi \times X\left(\mathrm{~cm}^{2}\right) / 2
$$

where $X$ represents the average area of the two images calculated using Image $J$ software. To validate this formula, we scanned some fruit with a 3D scanner (FARO Edge Scan Arm ES 9ft, FARO technologies Inc., Lake Mary, USA) and calculated the surface area using Magics software (Materialise, Frankfurt, Germany).

Fruit fresh weight, water content, and pericarp thickness

The initial water content of freshly harvested fruits and dry weight of fruits, of the same fruits using measurement of postharvest water loss, were determined by drying in an oven for $24 \mathrm{~h}$ at $105^{\circ} \mathrm{C}$. Five mature green fruits from every cultivar were cut across the center of the fruit and measured the thickness of the pericarp at five equal intervals across the cut sections.

\section{Microscope assay for cuticular characterization}

The sections of the pericarp were separated at approximately $60 \mu \mathrm{m}$ thickness near the tip of the six pepper fruits using a razor blade and micro slicer (DTK-3000, Dosaka-em Co. Ltd., Kyoto, Japan). In a preliminary study, the cuticular membrane of the fruit tip was the most developed among the various regions of the pepper fruit and the same trend was seen among varieties (data not shown). Ten sections of each cultivars were stained with Sudan IV for 2 min and then rinsed them with distilled water. The sections were mounted on slides in distilled water with a cover slip and then imaged and measured them using a microscope at five intervals in each section (VHX-2000, Keyence Co. Ltd., Osaka, Japan). As shown in Fig. 1, 
Table 1. Fruit characterization and cuticular thickness of 31 pepper cultivars.

\begin{tabular}{|c|c|c|c|c|c|c|}
\hline Cultivar & $\begin{array}{l}\text { Water loss } \\
\left(\mathrm{mg} \cdot \mathrm{cm}^{-2} 3 \mathrm{~d}^{-1}\right)\end{array}$ & $\begin{array}{l}\text { Fruit fresh } \\
\text { weight (g) }\end{array}$ & $\begin{array}{l}\text { Water } \\
\text { content (\%) }\end{array}$ & $\begin{array}{l}\text { Pericarp } \\
\text { thickness } \\
(\mathrm{mm})\end{array}$ & $\begin{array}{l}\text { Cuticular } \\
\text { thickness } a \\
(\mu \mathrm{m})\end{array}$ & $\begin{array}{l}\text { Cuticular } \\
\text { thickness } b \\
(\mu \mathrm{m})\end{array}$ \\
\hline Fushimi & $14.5 \pm 1.5$ & $12.1 \pm 0.5$ & $90.5 \pm 0.3$ & $1.7 \pm 0.0$ & $10.5 \pm 0.4$ & $40.2 \pm 0.6$ \\
\hline Manganji & $12.0 \pm 0.5$ & $44.5 \pm 1.5$ & $92.4 \pm 0.1$ & $2.4 \pm 0.1$ & $9.8 \pm 0.4$ & $20.7 \pm 2.9$ \\
\hline Takanotsume & $40.4 \pm 4.8$ & $2.8 \pm 0.2$ & $85.1 \pm 0.7$ & $1.0 \pm 0.0$ & $15.5 \pm 0.4$ & $72.5 \pm 1.9$ \\
\hline Fntonaga & $27.4 \pm 1.9$ & $11.9 \pm 0.9$ & $88.5 \pm 0.7$ & $1.7 \pm 0.1$ & $12.4 \pm 0.4$ & $114.8 \pm 2.2$ \\
\hline Nikko & $23.5 \pm 3.2$ & $4.2 \pm 0.3$ & $86.4 \pm 0.6$ & $1.1 \pm 0.1$ & $10.8 \pm 0.4$ & $61.0 \pm 1.4$ \\
\hline Ecuadorian & $7.0 \pm 1.7$ & $32.3 \pm 2.7$ & $90.9 \pm 0.3$ & $2.7 \pm 0.1$ & $15.1 \pm 0.9$ & $29.7 \pm 2.6$ \\
\hline S3155 & $7.7 \pm 1.1$ & $34.6 \pm 2.9$ & $93.4 \pm 0.2$ & $3.4 \pm 0.1$ & $12.8 \pm 0.5$ & $24.2 \pm 1.1$ \\
\hline S3157 & $29.4 \pm 4.6$ & $3.7 \pm 0.4$ & $90.7 \pm 0.2$ & $2.0 \pm 0.0$ & $7.8 \pm 0.3$ & $62.4 \pm 2.6$ \\
\hline S3159 & $17.7 \pm 2.6$ & $13.2 \pm 0.8$ & $89.6 \pm 0.5$ & $1.8 \pm 0.1$ & $14.2 \pm 0.5$ & $54.4 \pm 2.4$ \\
\hline S3172 & $35.6 \pm 2.4$ & $2.6 \pm 0.1$ & $81.8 \pm 1.1$ & $1.0 \pm 0.0$ & $14.4 \pm 0.3$ & $103.2 \pm 2.5$ \\
\hline S3175 & $12.7 \pm 0.9$ & $2.9 \pm 0.2$ & $89.7 \pm 0.7$ & $0.9 \pm 0.1$ & $16.6 \pm 0.6$ & $28.0 \pm 3.4$ \\
\hline S3187 & $15.0 \pm 2.2$ & $24.1 \pm 2.2$ & $92.9 \pm 0.1$ & $2.1 \pm 0.1$ & $11.9 \pm 0.4$ & $65.7 \pm 2.4$ \\
\hline S3194 & $12.3 \pm 2.4$ & $6.8 \pm 0.7$ & $89.4 \pm 1.1$ & $2.0 \pm 0.1$ & $15.4 \pm 0.4$ & $29.5 \pm 2.4$ \\
\hline S3197 & $11.1 \pm 0.4$ & $10.3 \pm 0.5$ & $90.0 \pm 1.1$ & $2.0 \pm 0.0$ & $14.4 \pm 0.6$ & $79.4 \pm 2.1$ \\
\hline S3202 & $29.1 \pm 3.3$ & $3.3 \pm 0.3$ & $89.2 \pm 0.4$ & $1.2 \pm 0.1$ & $13.1 \pm 0.4$ & $56.7 \pm 2.9$ \\
\hline S3204 & $31.1 \pm 4.2$ & $2.1 \pm 0.2$ & $89.6 \pm 0.3$ & $1.9 \pm 0.0$ & $16.4 \pm 0.7$ & $68.5 \pm 3.3$ \\
\hline S3223 & $19.8 \pm 4.5$ & $4.0 \pm 0.3$ & $89.9 \pm 0.3$ & $1.4 \pm 0.0$ & $10.3 \pm 0.7$ & $64.3 \pm 2.7$ \\
\hline S3225 & $20.9 \pm 2.0$ & $2.7 \pm 0.1$ & $87.5 \pm 1.1$ & $0.9 \pm 0.0$ & $13.7 \pm 0.4$ & $78.5 \pm 1.4$ \\
\hline S3226 & $15.6 \pm 1.7$ & $3.6 \pm 0.4$ & $87.9 \pm 1.0$ & $1.2 \pm 0.0$ & $17.8 \pm 0.6$ & $71.2 \pm 2.6$ \\
\hline S3227 & $12.7 \pm 0.5$ & $2.4 \pm 0.1$ & $89.4 \pm 0.3$ & $0.8 \pm 0.0$ & $8.8 \pm 0.3$ & $70.9 \pm 1.2$ \\
\hline S3229 & $32.2 \pm 2.3$ & $2.5 \pm 0.2$ & $88.0 \pm 0.3$ & $1.0 \pm 0.0$ & $11.0 \pm 0.4$ & $55.2 \pm 1.7$ \\
\hline S3313 & $33.8 \pm 2.3$ & $1.9 \pm 0.1$ & $82.8 \pm 0.7$ & $0.9 \pm 0.0$ & $18.1 \pm 0.3$ & $86.3 \pm 3.2$ \\
\hline S3340 & $50.2 \pm 4.1$ & $2.6 \pm 0.2$ & $82.5 \pm 1.3$ & $1.0 \pm 0.1$ & $16.0 \pm 0.6$ & $105.1 \pm 2.3$ \\
\hline S3344 & $36.5 \pm 4.4$ & $4.3 \pm 0.3$ & $81.0 \pm 0.7$ & $2.4 \pm 0.1$ & $21.0 \pm 0.4$ & $116.3 \pm 2.2$ \\
\hline S3583 & $7.4 \pm 0.7$ & $13.9 \pm 1.2$ & $93.7 \pm 0.1$ & $2.4 \pm 0.2$ & $10.9 \pm 0.4$ & $25.2 \pm 0.8$ \\
\hline S3586 & $18.0 \pm 1.5$ & $8.0 \pm 0.6$ & $85.4 \pm 0.7$ & $2.6 \pm 0.1$ & $13.3 \pm 0.4$ & $41.7 \pm 1.3$ \\
\hline S3592 & $34.6 \pm 4.4$ & $3.2 \pm 0.1$ & $87.5 \pm 0.6$ & $1.2 \pm 0.1$ & $11.0 \pm 0.5$ & $110.9 \pm 1.4$ \\
\hline FE20 & $6.8 \pm 0.7$ & $13.1 \pm 1.1$ & $91.7 \pm 0.2$ & $1.3 \pm 0.1$ & $11.5 \pm 0.4$ & $28.6 \pm 0.7$ \\
\hline FE26 & $8.8 \pm 1.4$ & $14.0 \pm 0.8$ & $92.7 \pm 0.2$ & $2.2 \pm 0.0$ & $10.5 \pm 0.4$ & $26.3 \pm 0.9$ \\
\hline FE89 & $15.3 \pm 2.1$ & $14.9 \pm 1.5$ & $91.0 \pm 0.3$ & $2.3 \pm 0.1$ & $12.7 \pm 0.4$ & $23.5 \pm 1.6$ \\
\hline FE115 & $13.9 \pm 1.2$ & $16.4 \pm 1.7$ & $90.7 \pm 0.4$ & $1.9 \pm 0.1$ & $11.1 \pm 0.3$ & $27.9 \pm 1.1$ \\
\hline \multicolumn{7}{|c|}{ Correlation between water loss } \\
\hline$r$ & - & $-0.69^{* *}$ & $-0.8^{* *}$ & $-0.47^{* *}$ & $0.30^{\mathrm{NS}}$ & $0.72^{* *}$ \\
\hline
\end{tabular}

Note: Abbreviations with S were genetic resources of the Plant Genetic and Breeding Laboratory, Shinshu University (Matsushima et al. 2009) and FE were breeding lines of the Biotechnology Research Department, Kyoto Prefectural Agriculture, Forestry and Fisheries Technology Research Center. Each value represents the average \pm standard errors. ${ }^{* *}$ and NS indicate significance at $P<0.01$ and non-significance using Spearman's rank test.

Fig. 1. Thickness $a$ and $b$ of the cuticular membrane of pepper fruit. [Colour online].

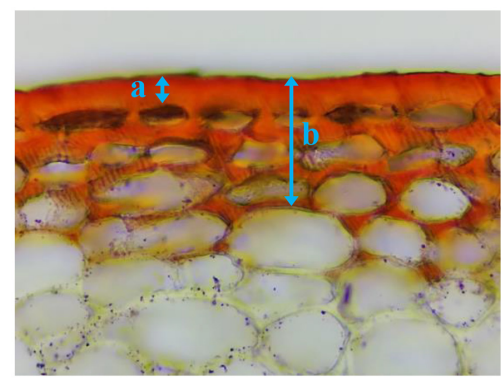

the aspects of the cuticle that we examined are as follows:

a. the thickness of the cuticular membrane, outside the epidermal cells;

b. the thickness of the cuticular membrane.

The sections of pericarp of approximately $5 \mathrm{~mm}$ thickness were separated near the tip of the fruit using a razor blade. The sections were transferred to $2 \%$ glutaraldehyde fixative ( $2 \%$ glutaraldehyde in $0.1 \mathrm{M}$ phosphate buffer, $\mathrm{pH}$ 7.4), which was then replaced with $50 \%$ ethanol. Sections were then transferred using a gradient 
of t-butyl alcohol followed by $50 \%$ ethanol, and then replaced with t-butyl alcohol. The sections were dried using freeze dehydration equipment (JFD-310; JEOL Co. Ltd., Tokyo, Japan). The prepared samples were observed using a scanning electron microscope (SEM) (JSM IT-200; JEOL Co. Ltd.) after coating them with Pt in an ionsputter coater (JEC-3000FC; JEOL Co. Ltd.).

Approximately $5 \mathrm{~mm}^{3}$ sections of pericarp were separated at the square pole from the middle region of the pepper fruit using a razor blade. The sections were fixed with $2.5 \%$ glutaraldehyde solution $(2.5 \%$ glutaraldehyde in $1 / 15 \mathrm{M}$ phosphate buffer, $\mathrm{pH} 7.2,3 \mathrm{~h}$ ), post-fixed with $\mathrm{OsO}_{4}$ solution $\left(1.0 \% \mathrm{OsO}_{4}\right.$ in $1 / 15 \mathrm{M}$ phosphate buffer, $\mathrm{pH}$ 7.2, $3 \mathrm{~h}$ ), dehydrated using a graded acetone series, replaced with propylene oxide, and embedded in epoxy resin at $38{ }^{\circ} \mathrm{C}$ overnight and $60^{\circ} \mathrm{C}$ for $24 \mathrm{~h}$. Ultrathin sections $(60 \mathrm{~nm})$ were created using a Leica UC7 ultramicrotome. These sections were mounted on copper grids and stained with $4 \%$ uranyl acetate for $16 \mathrm{~min}$ and Reynold's lead citrate for $8 \mathrm{~min}$ and observed with a transmission electron microscope (TEM) (JEM-1400 Plus; JEOL Co. Ltd.).

\section{Cuticle isolation}

The methods of Persons et al. (2012) for total cuticular extraction were modified. The representative eight cultivars, which varied in rate of water loss, and cut 10 square sections $(10 \mathrm{~mm} \times 10 \mathrm{~mm})$ from the center of the pepper fruit using a razor blade. The cuticular membrane from the sections were isolated using a mix of $0.1 \%(v / v)$ pectinase and $0.1 \%(v / v)$ cellulase (i.e., 2500 and 670 units $\cdot \mathrm{L}^{-1}$ of pectinase and cellulase, respectively) and $1 \mathrm{mM} \mathrm{NaN}_{3}$ to prevent microbial growth in a sodium citrate buffer (0.2 M, pH 3.8). Digestion took place in an incubator shaker set at $37{ }^{\circ} \mathrm{C}$ and $100 \mathrm{rpm}$ for $3 \mathrm{wk}$, and the enzyme solution was changed each week. The cuticular membrane were then separated from the pericarp, rinsed it in distilled water, and dried it at $50{ }^{\circ} \mathrm{C}$ for $48 \mathrm{~h}$. Five replications were performed for each cultivar.

\section{Total wax and cutin quantitation}

The methods of Chefetz (2003) for quantitative analysis of total wax, cutin, and polysaccharide with cutan were modified. The isolated cuticles were dewaxed with chloroform:methanol (1:1) at $50{ }^{\circ} \mathrm{C}$ for $5 \mathrm{~h}$. The dewaxed cuticles were rinsed in methanol, dried, and weighed. To remove cutin, the dewaxed cuticles were saponified with $1 \%$ potassium hydroxide in methanol at $35{ }^{\circ} \mathrm{C}$ for $48 \mathrm{~h}$. The non-saponifiable fraction was rinsed in methanol, dried, and weighed. The total wax and cutin contents were calculated by subtraction of the enzymatically isolated cuticular membrane, the dewaxed cuticles, and the non-saponifiable fractions. According to Tsubaki et al. (2013), the non-saponifiable fraction was regarded as polysaccharide with cutan.

\section{Texture analysis}

Eight cultivars that were used in cuticle isolation were used for texture analysis. The puncture force was evaluated using a creep meter (RE2-3305; Yamaden Co. Ltd., Tokyo, Japan) with a $20 \mathrm{~N}$ force cell, and a cylindrical flat-end plunger with $1.5 \mathrm{~mm}$ diameter, with a cross head speed of $0.5 \mathrm{~mm} \cdot \mathrm{s}^{-1}$. Data were analyzed using BAS-3305LE ver. 2.5 software (Yamaden Co. Ltd.). Pepper pieces $(1 \mathrm{~cm} \times 3 \mathrm{~cm})$ that were cut from the center of the fruit with a razor blade, were placed skin-side down. Measurements were repeated on 20 pieces of fruit from each cultivar.

\section{Turgor pressure of the pericarp}

The turgor pressure of the pericarp was calculated from the difference between the osmotic pressure and diffusion pressure deficit (DPD) of the fruit pericarp. DPD was analyzed using the Chardakov dye method and modified protocol of Yuda and Okamoto (1967). Two sets of five ranges of sucrose solutions were prepared. The pericarp tissue was placed in each solution of one set and left for $1 \mathrm{~h}$. A bit of methylene blue solution was added to the solution of the other set. A drop of the stained solution was layered on the first set of solutions, the tissue was removed, and the DPD was determined from how the stained drop was diluted in the solution. At the same time, the supernatant of the crushed fruits was stained, and the osmotic pressure was determined based on how the stained drop was diluted in the sucrose solution sets.

\section{Statistical analysis}

Statistical analyses were conducted using Statcel4 (Yanai 2015), an add-in for Microsoft Excel software. Correlation coefficients were calculated using Spearman's rank test.

\section{Results}

Surface area analysis

The surface area values calculated from the photographic images were closely correlated with the values from the 3D scanner data (Fig. 2). Therefore, we estimated the fruit surface area using the following revised formula

$$
\text { fruit surface area }\left(\mathrm{cm}^{2}\right)=1.0502(\pi \times X)-10.607
$$

where $X$ represents the average area of the two images.

Postharvest water loss and correlation with physical traits and thickness of the cuticular membrane

The water loss of 31 cultivars ranged from 6.8 to $50.2 \mathrm{mg} \mathrm{cm}^{-2}$ per $3 \mathrm{~d}$ (Table 1). A negative correlation between postharvest water loss and fruit fresh weight, and a weak negative correlation between water loss and pericarp thickness were found (Table 1). The thickness of the cuticular membranes varied from 7.8 to $21.0 \mu \mathrm{m}$ [(thickness $a$ ), outside the epidermal cells] and 20.7 to 
Fig. 2. Relationship between the surface area of fruit measured using different methods. (A) Surface area values calculated by 3D scanner data; (B) surface area values calculated from photographic images. $X=2 \times \pi \times X / 2$, where $X$ represents the average area of two images calculated using Image $\mathrm{J}$ software.

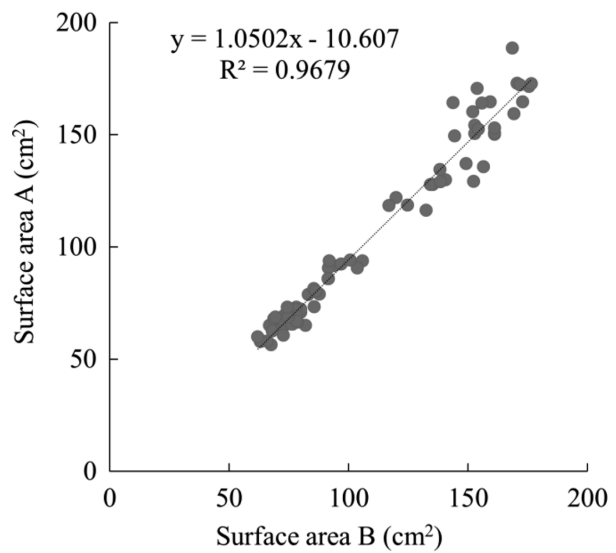

$116.3 \mu \mathrm{m}$ (thickness $b$ ) (Table 1). There was no correlation between water loss and the thickness of the cuticular membrane (thickness $a$, Fig. 1) but the thickness of the cuticular membrane along with the epidermal cells (thickness $b$ ) was strongly correlated with water loss (Table 1).

\section{Micromorphology of the pericarp epidermis}

Under the microscope, cuticular membrane that was stained by Sudan IV wedged between epidermal cells were observed (Figs. 3A and 3B). The cultivar Manganji had a thinner cuticular membrane wedged between epidermal cells (Fig. 3A) but S3340 had a thicker membrane between the fourth and fifth layers of subepidermal cells (Fig. 3B). Under a SEM, development of the cuticular membrane was observed in the same area stained by Sudan IV (Fig. 3C). Additionally, under a TEM, an amorphous fibrous structure was found in the cuticular layer vertically wedged between subepidermal cells (Figs. 3D and 3E).

\section{Total wax, cutin, and polysaccharide with cutan content}

The cuticular membrane consists of cutin polymer, with waxes that impregnate and cover the cutin, polysaccharides derived from the walls of epidermal cells, and cutan (Domínguez et al. 2011). In addition, in the pepper fruit, the cuticular membrane included the epidermal cells that are buried in cuticle. The weight of the cuticular membrane, and total wax, total cutin, and polysaccharide with cutan content of the eight selected cultivars were quantified under a range of water loss and cuticular membrane thickness conditions. The weight of the cuticular membrane ranged from 0.87 to $7.40 \mathrm{mg} \cdot \mathrm{cm}^{-2}$, and there were differences between cultivars (Table 2). There were positive correlations between water loss and cuticular membrane weight, total cutin weight, and polysaccharide with cutan weight (Table 2).

\section{Texture analysis}

The force-displacement curve of the pepper fruit is shown in Fig. 4. In this study, the force-displacement curve was divided into two phases based on the degree of inclination, according to Yoshikawa et al. (1982). Phase I was defined as the start of analysis to the small change in force with displacement, just before a rapid increase in force. Phase II was defined as the end of phase I to the maximum value of force, at which the plunger broke through the pericarp (Fig. 4). Table 3 shows that there was no correlation between the maximum force of phase II with the average force of phase I. However, there was a significant positive correlation between the maximum force and displacement of phase II.

There was a positive correlation between the average force of phase I and the thickness of the pericarp, but no correlation with turgor pressure of the pericarp (Table 4). A positive correlation was found between the maximum force of phase II with the weight of the cuticular membrane, cutin content, which was the main component of the cuticular membrane, and polysaccharidecutan content (Table 4). There was no correlation between the maximum force of phase II with wax content (Table 4). In addition, a positive correlation was found between the displacement of phase II with the weight of the cuticular membrane, cutin content, which was the main component of the cuticular membrane, and polysaccharide-cutan content (Table 4).

\section{Discussion}

It is clear from our results that the thickness and weight of the cuticular membrane is correlated with water loss (Tables 1 and 2). Leide et al. (2007) found a positive correlation between cuticle weight and water loss in tomato fruit. Parsons et al. (2012) found a positive correlation between total cutin content and fruit water loss. These results are consistent with our findings (Table 2). However, Maalekuu et al. (2005) found no correlation between fruit water loss and whole cuticle weight. Rate of water loss was expressed per unit surface area of the pericarp. Maalekuu et al. (2005) calculated the surface area based on the total pericarp weight and weight of a fixed area of the pericarp. However, this method is not precise because the thickness of the fixed area pericarp is not constant. Therefore, their results may have differed because the measurement method used was not appropriate.

Postharvest water loss was negatively correlated with fruit fresh weight (Table 1). This result may be because lower weight fruits tended to have a thicker cuticle than higher weight fruits in this study. Additionally, a positive correlation was found between the thickness of the cuticular membrane with water loss in similar-sized fruits (data not shown).

The cuticular membrane wedged between subepidermal cells (Figs. 3A and $3 \mathrm{C}$ ), and an amorphous fibrous structure in the cuticular layer wedged between 
Fig. 3. Micromorphology of the cuticular membrane in the pepper fruit cultivars Manganji (A) and S3340 (B-E). Scale bars indicate $30 \mu \mathrm{m}(\mathrm{A}, \mathrm{B}), 10 \mu \mathrm{m}(\mathrm{C}), 1 \mu \mathrm{m}$ (D), $200 \mathrm{~nm}$ (E). (E) is an enlarged view inside the square frame of (D). [Colour online].
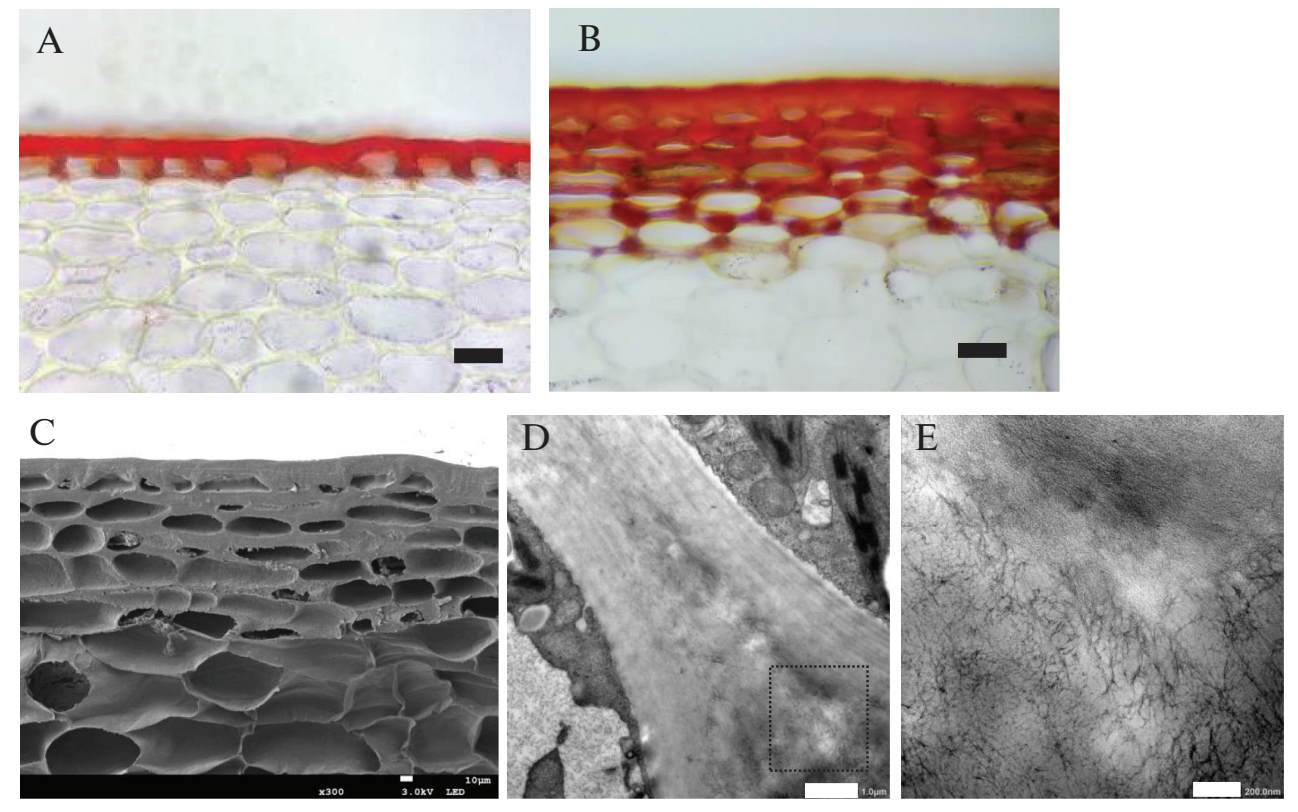

Table 2. Cuticle, wax, and cutin weight of pepper fruit.

\begin{tabular}{lccccc}
\hline Cater loss & $\begin{array}{l}\text { Cuticle } \\
\text { weight } \\
\left(\mathrm{mg} \cdot \mathrm{cm}^{-2}\right)\end{array}$ & $\begin{array}{l}\text { Total wax } \\
\text { weight } \\
\left(\mu \mathrm{g} \cdot \mathrm{cm}^{-2}\right)\end{array}$ & $\begin{array}{l}\text { Cutin } \\
\text { weight } \\
\left(\mu \mathrm{g} \cdot \mathrm{cm}^{-2}\right)\end{array}$ & $\begin{array}{l}\text { Polysaccharide } \\
\text { with cutan weight } \\
\left(\mu \mathrm{g} \cdot \mathrm{cm}^{-2}\right)\end{array}$ \\
\hline Fushimi & $14.5 \pm 1.5$ & $1.73 \pm 0.02$ & $51.8 \pm 2.4$ & $1369.4 \pm 20.9$ & $308.2 \pm 13.5$ \\
Manganji & $12.0 \pm 0.5$ & $1.61 \pm 0.10$ & $30.8 \pm 8.8$ & $1228.2 \pm 47.8$ & $347.6 \pm 46.9$ \\
Takanotsume & $40.4 \pm 4.8$ & $4.73 \pm 0.21$ & $33.8 \pm 5.5$ & $3849.4 \pm 166.8$ & $843.6 \pm 43.4$ \\
Futonaga & $27.4 \pm 1.9$ & $7.40 \pm 0.32$ & $217.0 \pm 21.5$ & $6142.4 \pm 276.3$ & $1037.6 \pm 42.8$ \\
Nikko & $23.5 \pm 3.2$ & $4.04 \pm 0.25$ & $334.8 \pm 171.2$ & $3051.4 \pm 94.7$ & $654.8 \pm 26.2$ \\
S3155 & $7.7 \pm 1.1$ & $0.87 \pm 0.02$ & $27.8 \pm 1.1$ & $606.8 \pm 19.5$ & $234.8 \pm 27.2$ \\
S3340 & $50.2 \pm 4.1$ & $7.28 \pm 0.06$ & $107.4 \pm 7.6$ & $5739.2 \pm 53.5$ & $1428.4 \pm 16.0$ \\
S3586 & $18.0 \pm 1.5$ & $1.91 \pm 0.02$ & $65.6 \pm 18.1$ & $1402.4 \pm 20.8$ & $437.0 \pm 15.0$ \\
\hline Correlation between water loss & & & & $0.93^{* *}$ & $0.95^{* *}$ \\
$r$
\end{tabular}

Note: Abbreviations with $S$ were genetic resources of the Plant Genetic and Breeding Laboratory, Shinshu University (Matsushima et al. 2009). Each value represents the average \pm standard errors. ${ }^{* *}$ and NS indicate significance at $P<0.01$ and non-significance using Spearman's rank test.

subepidermal cells were observed (Figs. 3D and 3E). Generally, the structure of the cuticular membrane, as viewed from the outer side, comprises a thin layer of epicuticular wax, lamellate cuticle proper, and cuticle layer with inhomogeneous structure. The cuticle layer has a bi-layered structure with external and internal layers, adjacent to the epidermal cell wall (Mérida et al. 1981; Bargel et al. 2006; Jeffree 2006). The cuticle proper, which contains wax and cutin, is the main barrier of the cuticle membrane (Riederer and Schreiber 2001; Bargel et al. 2006). The lamellate structure of the cuticle proper is presumed to be the path for molecules diffusing across the cuticle and there is no correlation between the thickness of the cuticle proper and its permeability (Baur et al. 1999). On the other hand, the cuticle layer, which contains cutin, wax, and polysaccharides, has an inhomogeneous reticular structure (Jeffree 2006), which adds little to the barrier properties (Baur et al. 1999).

In the present study, cultivars with thick cuticle development in the pericarp exhibited higher water loss (Table 1). In addition, the cuticle that wedged between subepidermal cells have amorphous and fibrous structures (Fig. 3). According to a report by Domínguez et al. (2011), the observed fibrous structure is polysaccharides derived from epidermal cells. Therefore, these results suggest that development of a 
Fig. 4. Parameters extracted from the force-distance curves of a texture analysis of pepper fruit. The curve was divided into two phases based on the degree of inclination. Phase I was defined as the start of analysis to the small change in force with displacement, just before the rapid increase in force. Phase II was defined as after phase I to the maximum value of force at which the plunger broke through the pericarp.

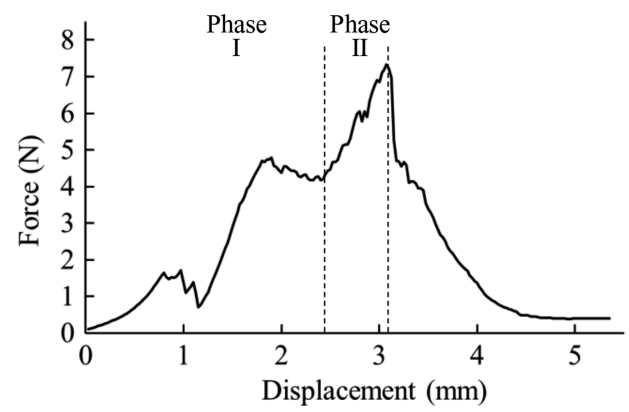

cuticle layer with limited barrier properties between the subepidermal cells, forms a path for diffusion and increases water loss.

It is known that pathways of water loss in fruit are the cuticular membrane, the calyx, and the stomata. In eggplant, there is a large amount of water loss from the calyx and correlations have been observed between the calyx area and the rate of water loss (Díaz-Pérez 1998). However, judging from our preliminary tests (data not shown), the contribution of the calyx to water loss was limited. Moreover, pepper fruit have few stomata (Weryszko-Chmielewska and Michałojć 2011), and no stomata were observed on pepper fruit used in this study. Therefore, most of the water loss from pepper fruit was through the cuticular membrane of the pericarp.

With a few exceptions, it is believed that pepper fruits with thin pericarp have thick cuticles because thick cuticles provide mechanical support to maintain the integrity of fruit organs. Pepper fruits with thick cuticles tend to lose water at a higher rate than that with thin cuticles, but fruits on trees do not shrivel during the growing period.

Even though it is assumed that cuticular thickness and weight are correlated to some extent, the most important factor for water loss across the pericarp may be the depth to which the cuticle extends into the anticlinal wall, permeating through the walls of the additional underlying epidermal cell layers. The contribution of the permeability of cutin, the main component of the cuticle, was much larger than that of wax (Schönherr 1976). Additionally, the solubility parameters of the ingredients comprising the cuticle increased in the order inner side, epicuticular wax, cuticle proper, cuticle layer (Khayet and Fernández 2012). Although wax from pepper fruit surface functions as a main barrier for water loss, shown by drastic increase of water loss from fruit dewaxed by chloroform (data was not shown), higher permeability of cuticle wedged deeply between subepidermal cells accelerate water loss. Therefore, rate of water loss depends on the thickness of cuticular membrane. This is the first report of a correlation between the visual thickness of the cuticular membrane and water loss in pepper fruit. In addition, cultivars with a thick cuticular membrane containing a lot of cutin and polysaccharide showed greater water loss.

In addition, a positive correlation was found between the average force of phase I, which indicates hardness of the mesocarp (Yoshikawa et al. 1982), and thickness of the pericarp. The turgor pressure of the pericarp was measured because higher turgor pressure has a higher compaction force in pericarp tissues, however, we found no correlation.

A positive correlation was found between the maximum force and displacement of phase II - indicating hardness and toughness of the exocarp, respectively (Yoshikawa et al. 1982) - and weight of the cuticular membrane (Table 3 ). In the many pepper cultivars, subepidermal cells of the exocarp buried in the cuticular membrane were observed. Therefore, fruits with a thick cuticle had a hard, tough texture (Tables 3 and 4). Moreover, $70 \%$ to $83 \%$ of the cuticular membrane weight was cutin and $14 \%$ to $23 \%$ was polysaccharides with cutan (Table 2). López-Casado et al. (2007) found that the cuticular membrane is a complex of cutin with polysaccharides and this complex possesses both elastic and viscoelastic properties, while stiffness is primarily provided by the polysaccharides; the cutin matrix imparts plasticity. These conclusions are in agreement with our findings that fruit with a high content of cutin and polysaccharides were tough and hard (Tables 3 and 4).

In this study, the puncture force was evaluated from inside to outside of the fruit because at the measurement from outside to inside the value of force is affected by pericarp thickness. When we eat fruits of pepper, teeth bites on the fruit are observed on both sides of the pericarp. In this case, soft flesh is crushed, and the hard parts of the pericarp are bit off. Therefore, hardness and toughness valued in this study coincide with the actual texture.

These results lead to the conclusion that the cuticular membrane has a close relationship with water loss and texture. Therefore, quantification of the cuticular membrane is important for breeding of pepper fruit for improvements in water loss and texture. In addition, for breeding of pepper, S3155 is a promising material with less water loss and tender fruit texture. Enzymes and these candidate genes of cuticle biosynthesis are already reported (Yeats and Rose 2013), but reports of quantitative trait loci (QTL) for development of cuticle in pepper is limited. QTL for the development of cuticles are necessary to make molecular marker for selection of water loss and texture. In this study, the composition of cutin and polysaccharide were not analyzed. Therefore, further research on the correlation between water loss 
Table 3. Texture analysis of pepper fruit.

\begin{tabular}{llll}
\hline Cultivar & $\begin{array}{l}\text { Average force } \\
\text { of phase I }(\mathrm{N})\end{array}$ & $\begin{array}{l}\text { Maximum force } \\
\text { of phase II }(\mathrm{N})\end{array}$ & $\begin{array}{l}\text { Displacement } \\
\text { of phase II }(\mathrm{mm})\end{array}$ \\
\hline Fushimi & $1.97 \pm 0.10$ & $4.79 \pm 0.48$ & $0.62 \pm 0.06$ \\
Manganji & $2.45 \pm 0.09$ & $4.09 \pm 0.40$ & $0.24 \pm 0.03$ \\
Takanotsume & $1.49 \pm 0.20$ & $7.04 \pm 0.90$ & $0.71 \pm 0.07$ \\
Futonaga & $2.28 \pm 0.10$ & $7.88 \pm 0.72$ & $0.87 \pm 0.06$ \\
Nikko & $1.47 \pm 0.14$ & $4.93 \pm 0.60$ & $0.54 \pm 0.05$ \\
S3155 & $2.85 \pm 0.08$ & $4.52 \pm 0.70$ & $0.23 \pm 0.02$ \\
S3340 & $0.85 \pm 0.05$ & $8.14 \pm 1.03$ & $1.01 \pm 0.04$ \\
S3586 & $1.75 \pm 0.14$ & $7.82 \pm 0.84$ & $0.92 \pm 0.08$ \\
\hline Correlation coefficient values & \multicolumn{3}{c}{$0.94^{\mathrm{NS}}$} \\
$r$
\end{tabular}

Note: Abbreviations with $S$ were genetic resources of the Plant Genetic and Breeding Laboratory, Shinshu University (Matsushima et al. 2009). Each value represents the average \pm standard errors. ${ }^{* *}$ and NS indicate significance at $P<0.01$ and non-significance using Spearman's rank test.

Table 4. Correlation coefficient values between the average force of phase I, maximum force of phase II, and displacement of phase II and the weight of cuticle, total wax, cutin, polysaccharide-cutan, thickness of pericarp, and turgor pressure of pericarp.

\begin{tabular}{lllllcr}
\hline & $\begin{array}{l}\text { Cuticle } \\
\text { weight }\end{array}$ & $\begin{array}{l}\text { Total wax } \\
\text { weight }\end{array}$ & $\begin{array}{l}\text { Cutin } \\
\text { weight }\end{array}$ & $\begin{array}{l}\text { Polysaccharide } \\
\text { with cutan weight }\end{array}$ & $\begin{array}{l}\text { Pericarp } \\
\text { thickness }\end{array}$ & $\begin{array}{l}\text { Turgor pressure } \\
\text { of pericarp }\end{array}$ \\
\hline Average force of phase I & - & - & - & - & $0.83^{*}$ & $-0.67^{\mathrm{NS}}$ \\
Maximum force of phase II & $0.88^{* *}$ & $0.67^{\mathrm{NS}}$ & $0.88^{* *}$ & $0.86^{*}$ & $-0.60^{\mathrm{NS}}$ & $0.53^{\mathrm{NS}}$ \\
Displacement of phase II & $0.76^{*}$ & $0.54^{\mathrm{NS}}$ & $0.76^{*}$ & $0.76^{*}$ & $-0.52^{\mathrm{NS}}$ & $0.34^{\mathrm{NS}}$ \\
\hline
\end{tabular}

Note: ${ }^{* *},{ }^{*}$ and NS indicate significance at $P<0.01, P<0.05$ and non-significance using Spearman's rank test.

with each component of cutin and polysaccharide is required.

\section{Acknowledgments}

We would like to thank Dr. K. Matsushima of Shinshu University for providing the pepper genetic resource, Dr. S. Date of Kyoto prefectural University for direction on specimen preparation of TEM and Dr. N. Furutani of Kyoto Prefectural Biotechnology research Department for advises in texture analysis.

\section{References}

Bargel, H., Koch, K., Cerman, Z., and Neinhuis, C. 2006. Structure-function relationships of the plant cuticle and cuticular waxes-a smart material? Funct. Plant Biol. 33: 893-910. doi:10.1071/FP06139. PMID:32689300.

Baur, P., Marzouk, H., and Schönherr, J. 1999. Estimation of path length for diffusion of organic compounds through leaf cuticles. Plant Cell Environ. 22: 291-299. doi:10.1046/j.13653040.1999.00429.x.

Chaïb, J., Devaux, M.F., Grotte, M.G., Robini, K., Causse, M., Lahaye, M., and Marty, I. 2007. Physiological relationships among physical, sensory, and morphological attributes of texture in tomato fruits. J. Exp. Bot. 58: 1915-1925. doi:10.1093/jxb/erm046. PMID:17452757.
Chefetz, B. 2003. Sorption of phenanthrene and atrazine by plant cuticular fractions. Environ. Toxicol. Chem. 22: 2492-2498. doi:10.1897/02-461. PMID:14552015.

Díaz-Pérez, J.C. 1998. Transpiration rates in eggplant fruit as affected by fruit and calyx size. Postharvest Biol. Technol. 13: 45-49. doi:10.1016/S0925-5214(97)00078-1.

Domínguez, E., Cuartero, J., and Heredia, A. 2011. An overview on plant cuticle biomechanics. Plant Sci. 181: 77-84. doi:10.1016/j.plantsci.2011.04.016. PMID:21683870.

Hernández-Carrión, M., Hernando, I., and Quiles, A. 2014. High hydrostatic pressure treatment as an alternative to pasteurization to maintain bioactive compound content and texture in red pepper. Innov. Food Sci. Emerg. Technol. 26: 76-85. doi:10.1016/j.ifset.2014.06.004.

Isaacson, T., Kosma, D.K., Matas, A.J., Buda, G.J., He, Y., Yu, B., et al. 2009. Cutin deficiency in the tomato fruit cuticle consistently affects resistance to microbial infection and biomechanical propertied, but not transpirational water loss. Plant J. 60: 363-377. doi:10.1111/j.1365-313X.2009.03969.x. PMID:19594708.

Jeffree, C.E. 2006. The fine structure of the plant cuticle. Pages 11-125 in Biology of the plant cuticle. Riederer and Müller, ed. Blackwell, Oxford.

Khayet, M., and Fernández, V. 2012. Estimation of the solubility parameters of model plant surface and agrochemicals: a valuable tool for understanding plant surface interactions. Theor. Biol. Med. Modell. 9: 45. doi:10.1186/1742-4682-9-45.

Leide, J., Hildebrandt, U., Reussing, K., Riederer, M., and Vogg, G. 2007. The developmental pattern of tomato fruit wax 
accumulation and its impact on cuticular transpiration barrier properties: effect of a deficiency in a $\beta$-ketoacyl-coenzyme A synthase (LeCER6). Plant Physiol. 144: 1667-1679. doi:10.1104/pp.107.099481. PMID:17468214.

López-Casado, G., Matas, A.J., Domínguez, E., Cuartero, J., and Heredia, A. 2007. Biomechanics of isolated tomato (Solanum lycopersicum L.) fruit cuticles: the role of the cutin matrix and polysaccharides. J. Exp. Bot. 58: 3875-3883. doi:10.1093/ jxb/erm233. PMID:17975209.

Lownds, N.K., Banaras, M., and Bosland, P.W. 1993. Relationship between postharvest water loss and physical properties of pepper fruit (Capsicum annuum L.). HortSci. 28: 1182-1184. doi:10.21273/HORTSCI.28.12.1182.

Lownds, N.K., Banaras, M., and Bosland, P.W. 1994. Postharvest water loss and storage quality of nine pepper (Capsicum) cultivars. HortSci. 29: 191-193. doi:10.21273/HORTSCI.29.3.191.

Maalekuu, K., Elkind, Y., Tuvia-Alkalai, S., Shalom, Y., and Fallik, E. 2004. The influence of harvest season and cultivar type on several quality traits and quality stability in three commercial sweet bell peppers during the harvest period. Adv. Hortic. Sci. 18: 21-25.

Maalekuu, K., Tuvia-Alkalai, S., Shalom, Y., and Fallik, E. 2005. Characterization of physiological and biochemical factors associated with postharvest water loss in ripe pepper fruit during storage. J. Am. Soc. Hortic. Sci. 130: 735-741. doi:10.21273/JASHS.130.5.735.

Matsushima, K., Tsuji, A., Sarinum, O., Minami, M., Nemoto, K., and Ikeno, M. 2009. Evaluation of genetic resources of chili pepper (Capsicum spp.). Boll. Shinshu Univ. AFC: 77-86. [in Japanese].

Mérida, T., Schönherr, J., and Schmidt, H.W.1981. Fine structure of plant cuticles in relation to water permeability: the fine structure of the cuticle of Clivia miniate Reg. Planta, 152: 259-267. doi:10.1007/BF00385154. PMID:24302425.

Papageorge, L.M., Mcfeeters, R.F., and Fleming, H.P. 2003. Factors influencing texture retention of sait-free, acidified red peppers during storage. J. Agric. Food Chem. 51: 1460-1463. doi:10.1021/jf025788e. PMID:12590498.

Parsons, E.P., Popopvsky, S., Lohrey, G.T., Lü, S., Alkalai-Tuvia, S., Perzelan, Y., et al. 2012. Fruit cuticle lipid composition and fruit post-harvest water loss in an advanced backcross generation of pepper (Capsicum sp.). Physiol. Plant. 146: 15-25. doi:10.1111/j.1399-3054.2012.01592.x. PMID:22309400.

Riederer, M., and Schreiber, L. 2001. Protecting against water loss: analysis of the barrier properties of plant cuticles. J. Exp. Bot. 52: 2023-2032. doi:10.1093/jexbot/52.363.2023. PMID:11559738.

Saladié, M., Matas, A.J., Isaacson, T., Jenks, M.A., Goodwin, S.M., Niklas, K.J., et al. 2007. A reevaluation of the key factors that influence tomato fruit softening and integrity. Plant Physiol. 144: 1012-1028. doi:10.1104/pp.107.097477. PMID:17449643.

Schönherr, J. 1976. Water permeability of isolated cuticular membranes: the effect of cuticular waxes on diffusion of water. Planta, 131: 159-164. doi:10.1007/BF00389989. PMID:24424766.

Smith, D.L., Stommel, J.R., Fung, R.W.M., Wang, C.Y., and Whitaker, B.D. 2006. Influence of cultivar and harvest method on postharvest storage quality of pepper (Capsicum annuum L.) fruit. Postharvest Biol. Technol. 42: 243-247. doi:10.1016/j.postharvbio.2006.06.013.

Tsubaki, S., Sugimura, K., Teramoto, Y., Yonemori, K., and Azuma, J. 2013. Cuticular membrane of Fuyu persimmon fruit is strengthened by triterperoid nano-fillers. PLoS ONE, 8: e75275. doi:10.1371/journal.pone.0075275. PMID:24086493.

Weryszko-Chmielewska, E., and Michałojć, Z. 2011. Anatomical traits of sweet pepper (Capsicum annuum L.) fruit. Acta Agrobot. 64: 181-188. doi:10.5586/aa.2011.059.

Yanai, H. 2015. Statistical analysis for Excel. OMS, Tokyo, Japan. pp. 197-210 [in Japanese].

Yeats, T.H., and Rose, J.K. 2013. The formation and function od plant cuticles. Plant Physiol. 163: 5-20. doi:10.1104/ pp.113.222737. PMID:23893170.

Yoshikawa, H., Kamimura, S., and Ito, K. 1982. Studies on fruit firmness of $F_{1}$ hybrids in Tomatoes. Bull. Vegetable and ornamental crops research Sta. in Japanese. English. Abstract B4: 1-14.

Yuda, E., and Okamoto, S. 1967. The determination of the D.P.D. of Satsuma orange leaves (Citrus unshiu MARC.) by the Chardakov Dye method. J. Japan. Soc. Hort. Sci. 36: 385-388. 